\title{
NBSIR 76-995(R)
}

\section{Guidelines for the Design and Procurement of a Low Cost Mobile Robot}

John M. Evans, Jr., Ph.D.

James $\mathrm{S}$. Albus, Ph. D.

Office of Developmental Automation and Control Technology Institute for Computer Sciences and Technology

National Bureau of Standards

Washington, D. C. 20234

December, 1975

Final

Prepared for

Naval Explosive Ordnance Disposal Facility

Indian Head, Maryland 20640 



\section{GUIDELINES FOR THE DESIGN AND PROCUREMENT OF A LOW COST MOBILE ROBOT}

John M. Evans, Jr., Ph.D. James S. Albus, Ph.D.

Office of Developmental Automation and Control Technology Institute for Computer Sciences and Technology National Bureau of Standards Washington, D. C. 20234

December, 1975

Final

Prepared for

Naval Explosive Ordnance Disposal Facility Indian Head, Maryland 20640

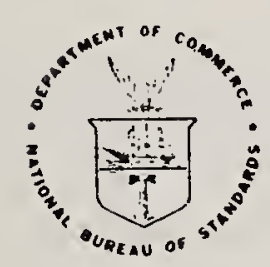

U.S. DEPARTMENT OF COMMERCE, Rogers C. B. Morton, Secretary James A. Baker, III, Under Secretany Dr. Botsy Ancker-Johnson, Assistant Secretary for Scionce and Technology NATIONAL BUREAU OF STANDARDS, Emest Ambler, Acting Director 

Since FY1973 the National Bureau of Standards has been supporting the Naval Explosive Ordnance Disposal Facility in the development of remote control manipulator systems for handling explosive ordnance. The use of remote automation systems allows human operators to remain in a safe location while only the mechanical robot system is directly exposed to the hazardous environment.

In this project, NBS set performance standards and specifications and managed the competitive procurement of the components of a high performance remote control manipulator system based on the Naval Anthropomorphic Teleoperator (NAT) manipulator.

During the course of this work, the Navy requested that NBS also develop a minimum cost manipulator system that could be procured at a minimum cost and thus could be considered expendable. NBS was unable to find any industry or research organization that felt that the cost targets considered would be possible.

NBS therefore undertook to demonstrate the feasibility of using standardized commercially available components to design a robot manipulator. The result was the Low Cost Mobile Robot (LMR).

The Low Cost Mobile Robot (LMR) can maneuver through a room, travel through doors, and climb stairs. The LMR carries a closed circuit TV camera so that its operator can smoothly and precisely pick up and move objects weighing up to 35 pounds.

The unique feature of the LMR is its extremely simple and low cost design. The LMR is constructed from inexpensive commercial components which can be purchased in a neighborhood hardware store or bicycle shop:

- The motors are commercial hand drills.

- The wrist flex is an automobile universal joint.

- The wrist roll and wheel bearings are commercial garden tractor bearings.

- The wheels are ordinary bicycle wheels.

- The frame is standard aluminum I-beam and angle iron.

The use of commercial components, and construction along simple lines has resulted in a robot system which we estimate could be procured in single quantity from commercial sources for less than $\$ 4$ thousand. This is more than an order of magnitude less expensive than presently available devices with similar capabilities. The cost savings to the Navy on a purchase of 100 robots would thus exceed $\$ 3$ million.

The robot is designed so that the wires from the control unit can be plugged into a smal1 computer to record repetitious operations that can be played back under computer control.

The LMR represents the beginning of a family of computer controlled robot devices that can assist Federal agencies to meet their mission objectives at less cost. Computer controlled robots could be designed around the same basic principles for:

- Explosive ordnance production, maintenance, and disposal;

- Mining and mine rescue;

- Undersea exploration and completing oil wells at depths beyond which divers can operate;

- Handling tasks in reprocessing radioactive nuclear fuel from breeder reactors;

- Space exploration; and 
- Handling caustic chemicals or red hot steel ingots in foundries or otherwise meeting OSHA requirements in a cost effective manner.

This report provides guidelines that the Navy can use in further development and competitive procurement of low cost robot manipulators. 
The general guideline for design of systems for low volume production is to use standard components that are already in high volume production for some other purpose. Hence, hand drills, garden tractor bearings, bicycle wheels, automobile universal joints, and closed circuit TV sets are inexpensive because they are already mass produced. Designing around such inexpensive, standardized commercial components is the key to cost reduction of the total system.

The design goals were set as follows:

1. Minimum total cost.

2. Manipulator to pick up 20 1b. cylindrical objects and place them in a basket container (scenario for explosive ordnance).

3. Vehicle to maneuver inside a building, including traveling through doors and climbing stairs.

4. Remote operation and closed circuit TV for remote viewing.

A11 of these goals were considered subsidiary to the first one of minimum cost. A11 were achieved except for stair climbing, which was successful only on shallow (6"X12") stairs. Further modifications being undertaken by the Navy should solve this deficiency.

The general design decisions were as follows:

1. Make maximum use of commerical components.

2. Use external power source (battery power led to weight and power penalties that were considered too severe).

3. Use direct cable control (no telemetry).

4. Provide six degrees of freedom (arbitrary position and orientation of the hand) plus grip.

5. Use the mobility system for two degrees of freedom for the manipulator.

6. Speed of operation of each degree of freedom to be approximately 2 seconds for ful1 lock to lock motions.

7. Use light cuing instead of stereo TV; avoid force feedback in first model.

These decisions led to the configuration shown in Figure 1. 


\section{FIGURE 1}

Low Cost Mobile Robot (LMR)

Shown during testing at NBS. Only 1 camera is shown; eventually two were provided. The LMR can pick up 35 lbs. and position it with an accuracy of $\pm 1 / 8^{\prime \prime}$. 


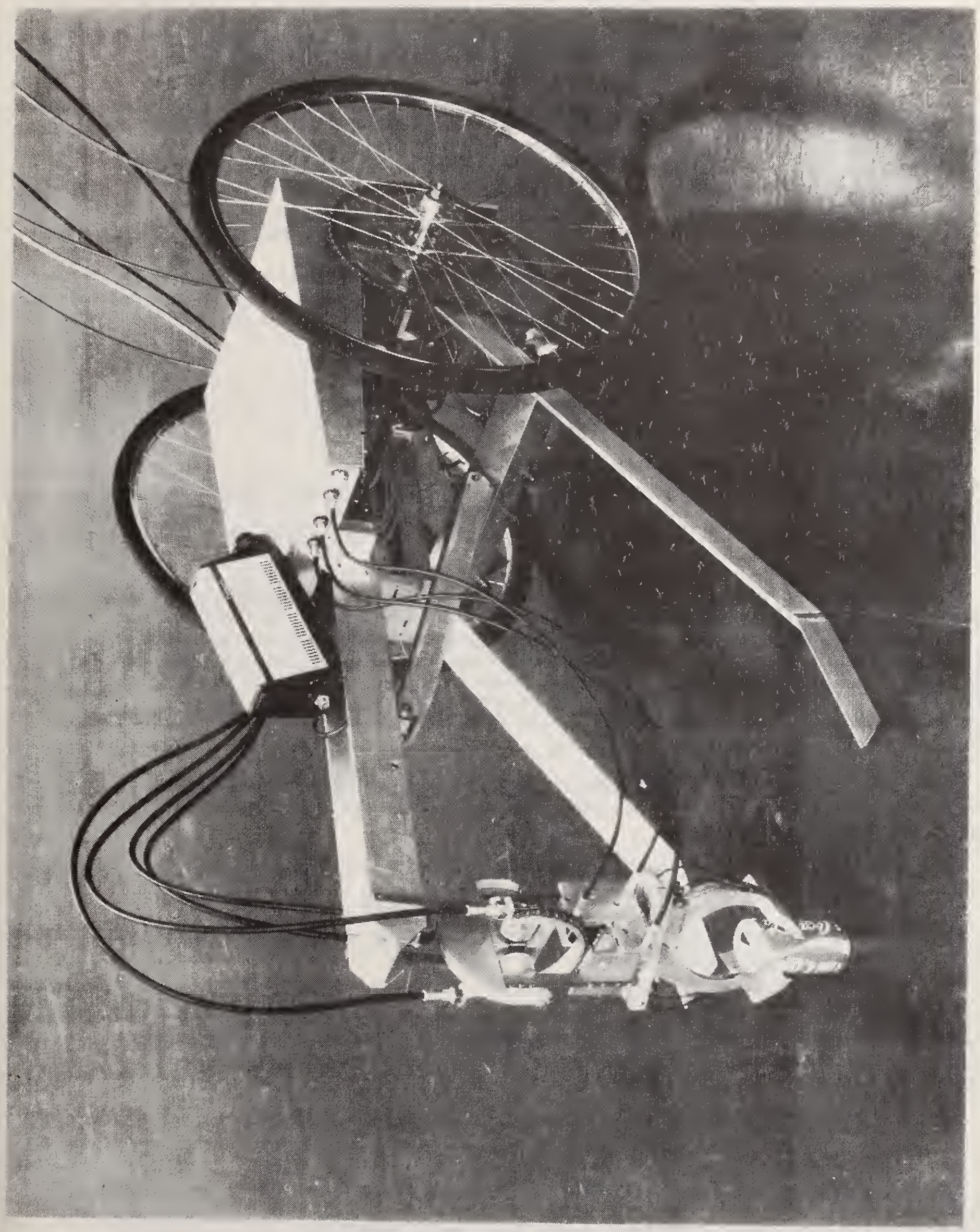


Details of the mechanical design are provided by a set of drawings that are not included in this report. Commercial items such as aluminum I-beam and angle stock are the principal components. All fabrication operations are specified; however, lower cost for low volume prototype production could be obtained by specifying "fit at assembly" for many drilling and other fabrication operations.

The details of mechanical design are shown in the accompanying photographs.

All motors and gear boxes are from commercial reversing hand drills. These are the least expensive universal motors and gear boxes that could be found. Backlash was small enough to be acceptable and the electronics design compensates for the high inertia of the motors. Since 7 degrees of freedom are involved in all, minimum cost in the motors are considered essential to overall cost control.

The motors are mounted together on one plate; coupling to the arm and hand is by commercial wire cables. See Figure 2.

The simplest vehicle configuration is two wheels with skids to support a load. By locating one motor on each wheel, drive and steering functions can be combined. This makes the axle passive and removes the need for a differential and for steering articulations. Differential drive steering gives an optimal situation of zero turning radius.

Obstacle climbing for such a vehicle may be approximated as a four wheel vehicle with front wheel drive (assuming no resistance in the shids). Analysis shows this approaches $h / d=1 / 2$ for wheel diameter $d$ and obstacle height $h . *$ The problem in obstacle or stair climbing is the transfer of weight to the skids, reducing the purchase of the wheels. The center of gravity moves back toward the skids as the tangent of the climbing angle. As the center of gravity approaches the skids, the system becomes unstable; the vehicle will refuse to climb before this point. The addition of tracks should improve performance.

Power for stair climbing is available: assuming $50 \%$ efficiency in transmission of power to the wheels, the $3 / 8^{\prime \prime}$ drills used should drive the vehicle up stairs with 6" risers at about $2 \mathrm{mph}$.

The two motors driving the wheels are mounted in opposition below the vehicle and drive the wheels with commercial chains. See Figure 3.

The 5 motors for the arm and wrist and grasp are mounted in a row on a mounting plate behind the axle as a counterbalance. They are enclosed in a box with a fan for cooling during stall operations.

The arm is pivoted on the axle and lift is provided by a cross member attached to the frame at one end and sliding with a linear ball bushing on a shaft at the other. The cable for this motion runs along the top of the arm I-beam and around pulleys through the I-beam web. Figures 4 and 5 show this detail.

Smoother operation of the arm lift with heavy loads could be obtained by replacing the shaft and ball bushing with a ball screw drive.

Figures 6 and 7 show the wrist assembly. The wrist is designed with a universal joint followed by a rotary motion of the hand (which can be called a flex-flex-roll configuration). This design is operationally equivalent to the human wrist, which has two perpendicular bending motions following a rotary motion of the forearm (and which would thus be called a ro11-flex-flex design). To contrast this with another design, the Navy NAT arms have a rotary motion in both the forearm and the hand and the wrist has a single bending motion (rol1-flex-rol1). This NAT design is more difficult to operate.

* Bekker, M.G., Theory of Land Locomotion, Ann Arbor, University of Michigan Press, 1956. 
The wrist is based on an automobile universal joint. Semicircular arcs are attached to the universal joint and operated in a pu11-pull manner for each axis. This design allows a constant moment arm for delivering torque to each axis. A section of bicycle chain provides a roller bearing surface for the cable operating the lower half of the joint.

The wrist roll, shown in detail in Figure 8, is based on commercial garden tractor bearings. The cable is wrapped around the wrist and secured around a screw. The control bearing shaft is hollow to allow the cable for the grip operation to pass through.

The hand, shown in Figure 9, is designed for large cylindrical objects and has 3 fingers for limited adaptability to varying objects. The fingers are spring loaded to open and are operated with a sinqle cable for the grip function.

An improvement in the design would be a quick disconnect wrist that would allow special tooling to be attached for different tasks. No gripper design can be universally useful.

Two devices improve visibility and operator performance with remote TV: painting the fingers white and mounting lamps on the hand. The lamps cast pools of light on an object being grasped giving an indication of the proximity of the hand to the object. This overcomes some of the difficulties in lack of depth perception with closed circuit TV.

There are several key features of this mechanical design:

1. Drill motors and gears for low cost.

2. Direct drive at wheels; differential drive for steering. The wheels are used to provide two of the motions of the manipulator.

3. All motors are grouped together at the axle for counterbalancing and ease of assembly.

4. The wrist structure is flex-flex-roll for ease of control.

5. All of the structure is standard aluminum I-beam and angle stock. 


\section{FIGURE 2}

\section{Top View of LMR with Cover Removed}

This view shows the gear boxes and feedback pots for the 5 motions of the arm and hand. These motions are operated by wire cables swaged to chains driven by sprockets pinned to the output shafts of the gear boxes.

The central motor drives the arm lift, the far left motor operates the grip. The grip is spring loaded open, so only one direction of drive is provided. The long spring keeps tension on the drive chain, the other provides gripping force without overloading the drive motor.

The electronics are contained in the box to the right of the arm. At the rear of the robot a junction box and power supply are located.

The mounting of the two TV cameras is shown. 


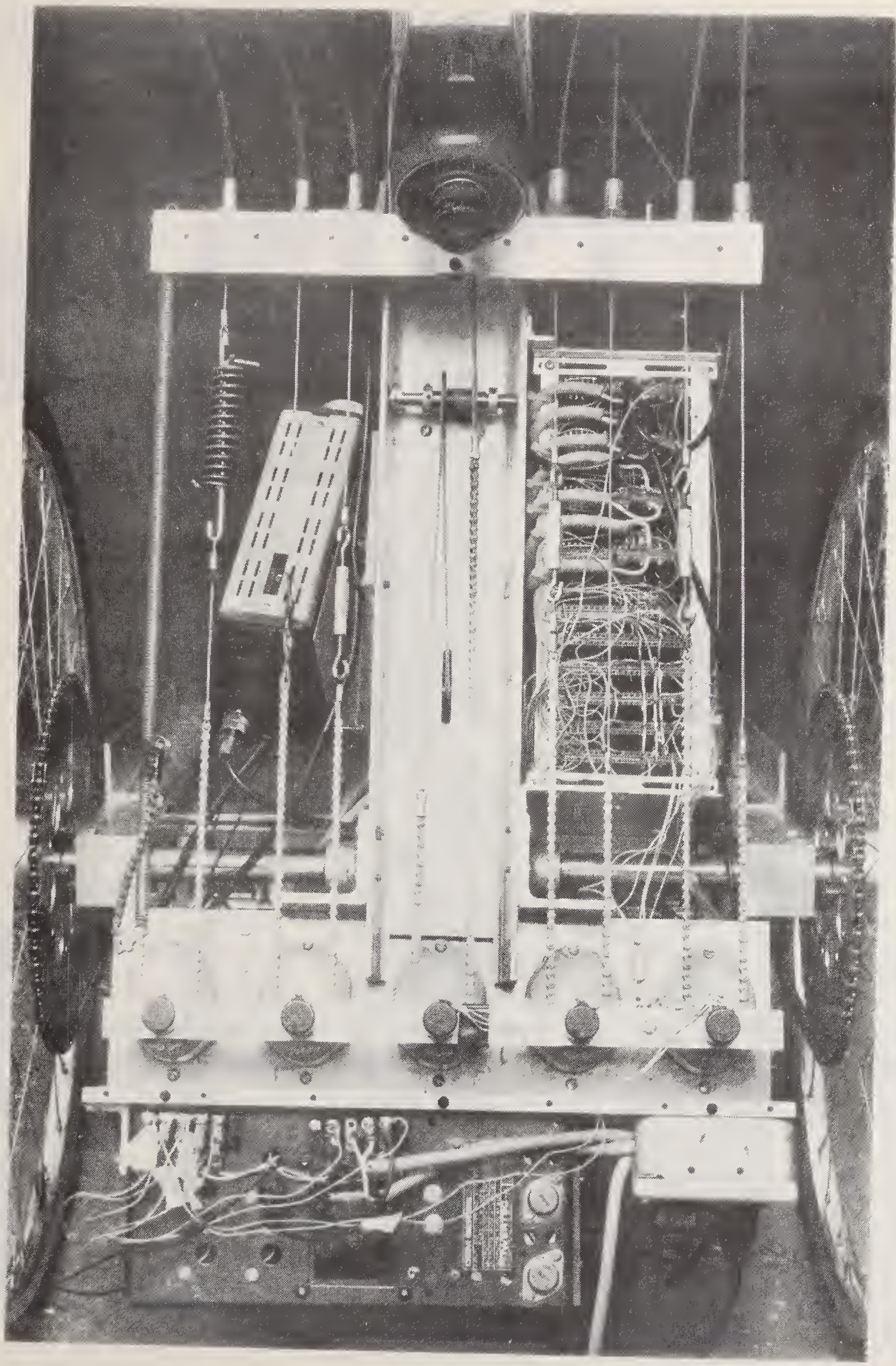


FIGURE 3

\section{LMR Bottom View}

All of the drive motors are shown. The $5 \mathrm{arm}$ and hand motors are enclosed in a box with forced air flow for cooling. 


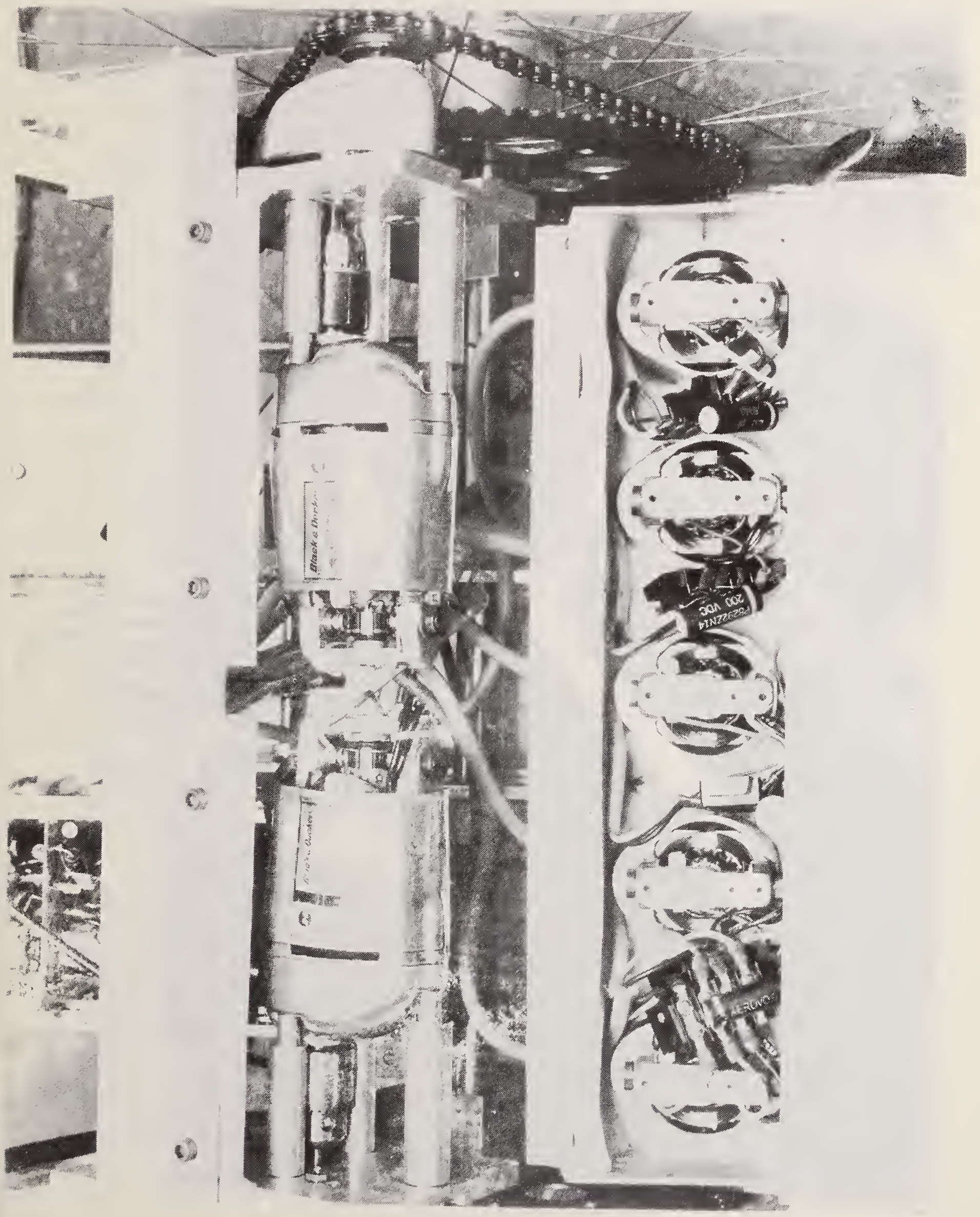




\section{FIGURE 4}

Side View Showing Arm Lift 


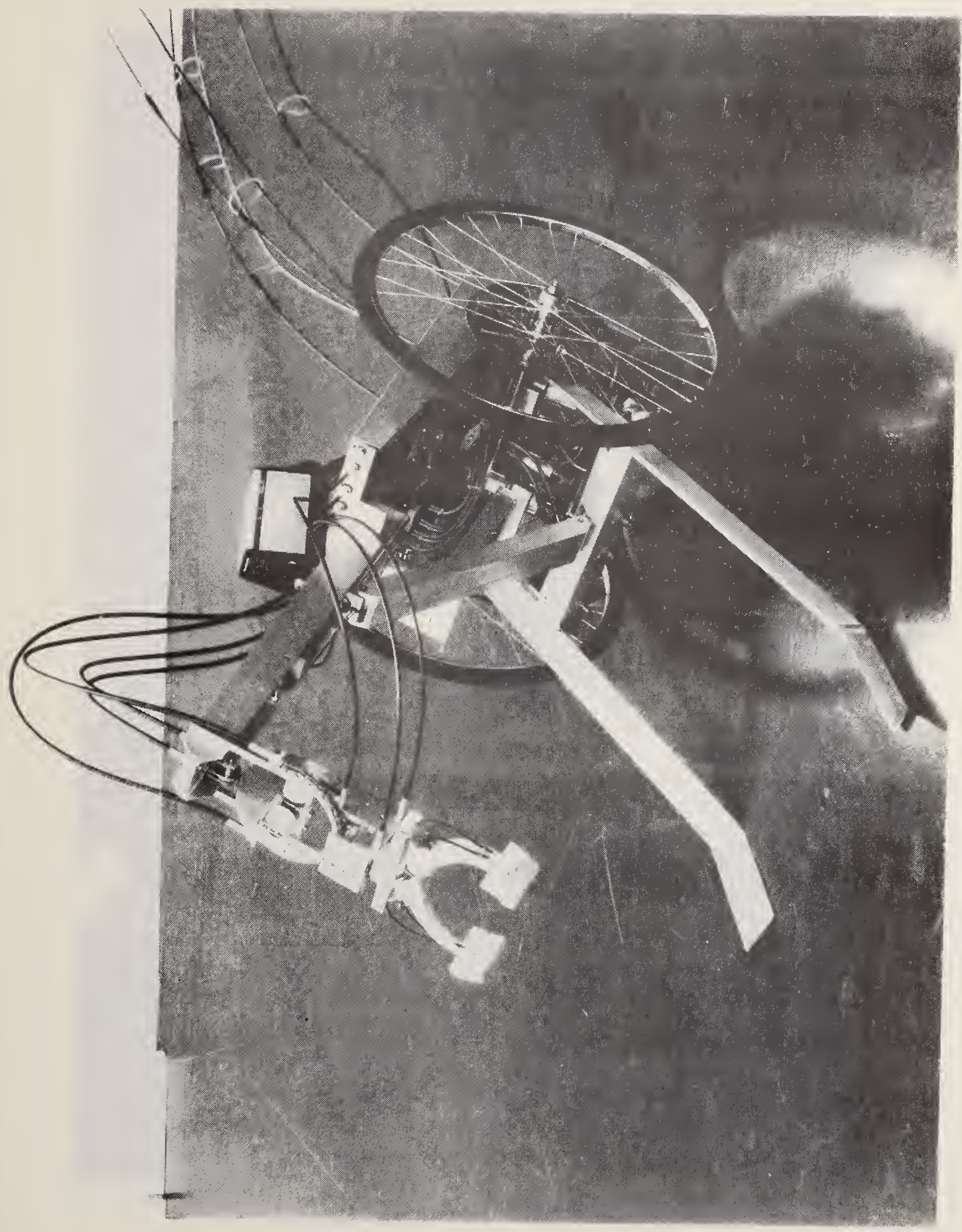


FIGURE 5

Arm Lift Detai] 


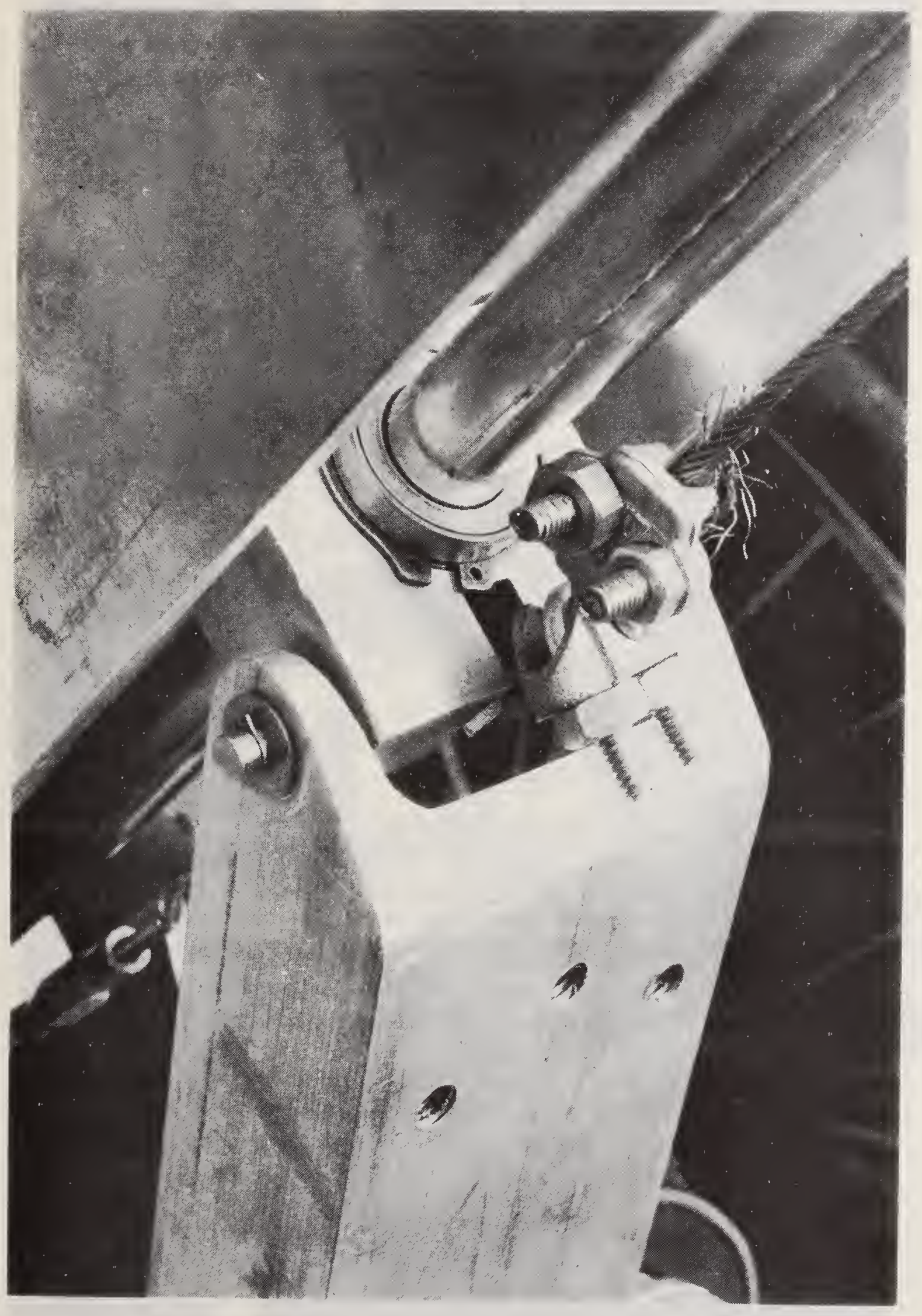




\section{FIGURE 6}

\section{Wrist and Hand Structure}

The wrist is built around an automobile universal joint. Two semicircular arcs provide a constant lever arm for applying torques about these axes. The chain provides a roller bearing surface for the cable.

The wrist roll contains garden tractor bearings. The shaft is hollow to allow passage of the single grip cable, which enters from the right and passes over a pulley and down to the grip. 


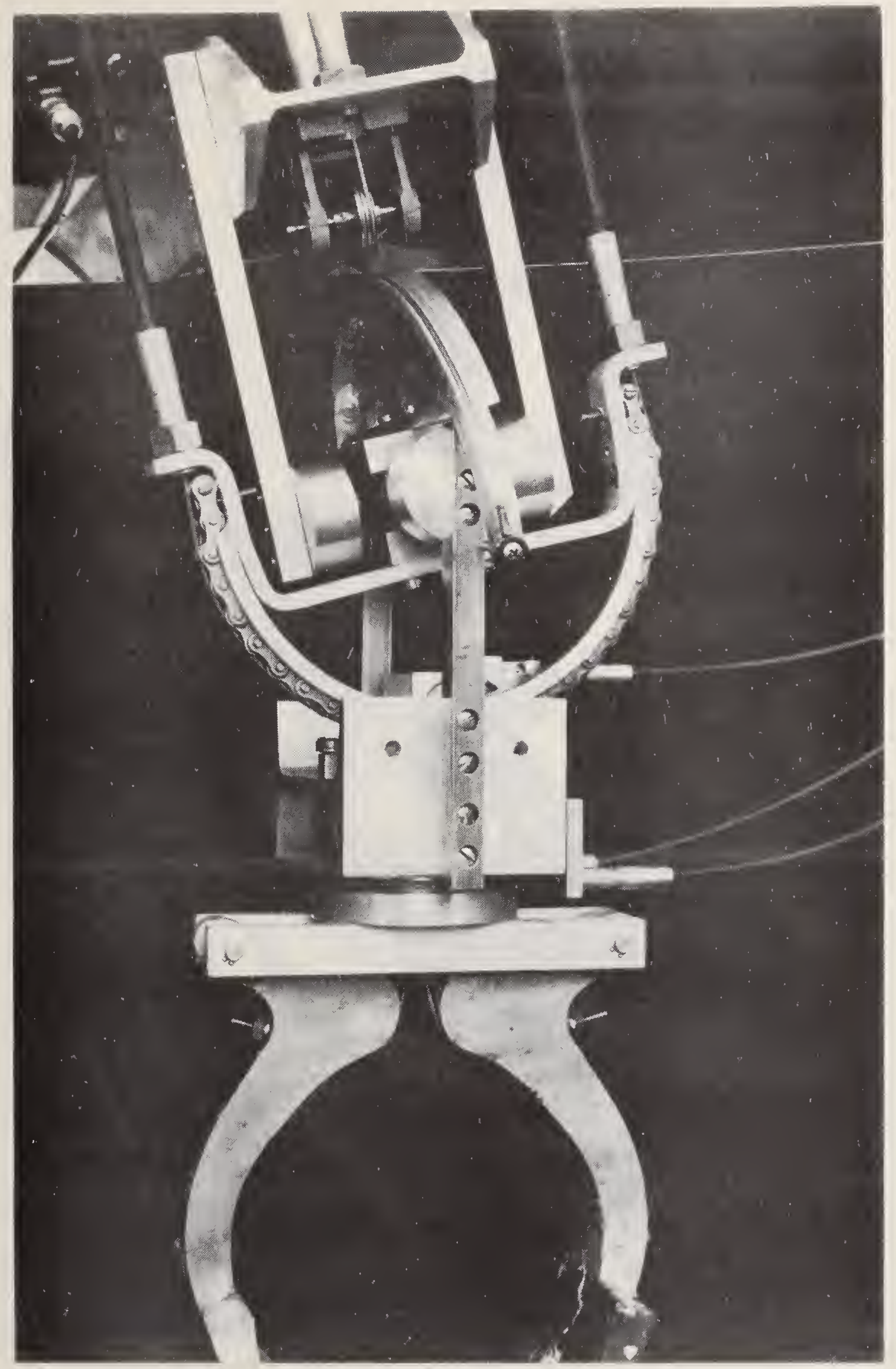


FIGURE 7

Wrist Detail 


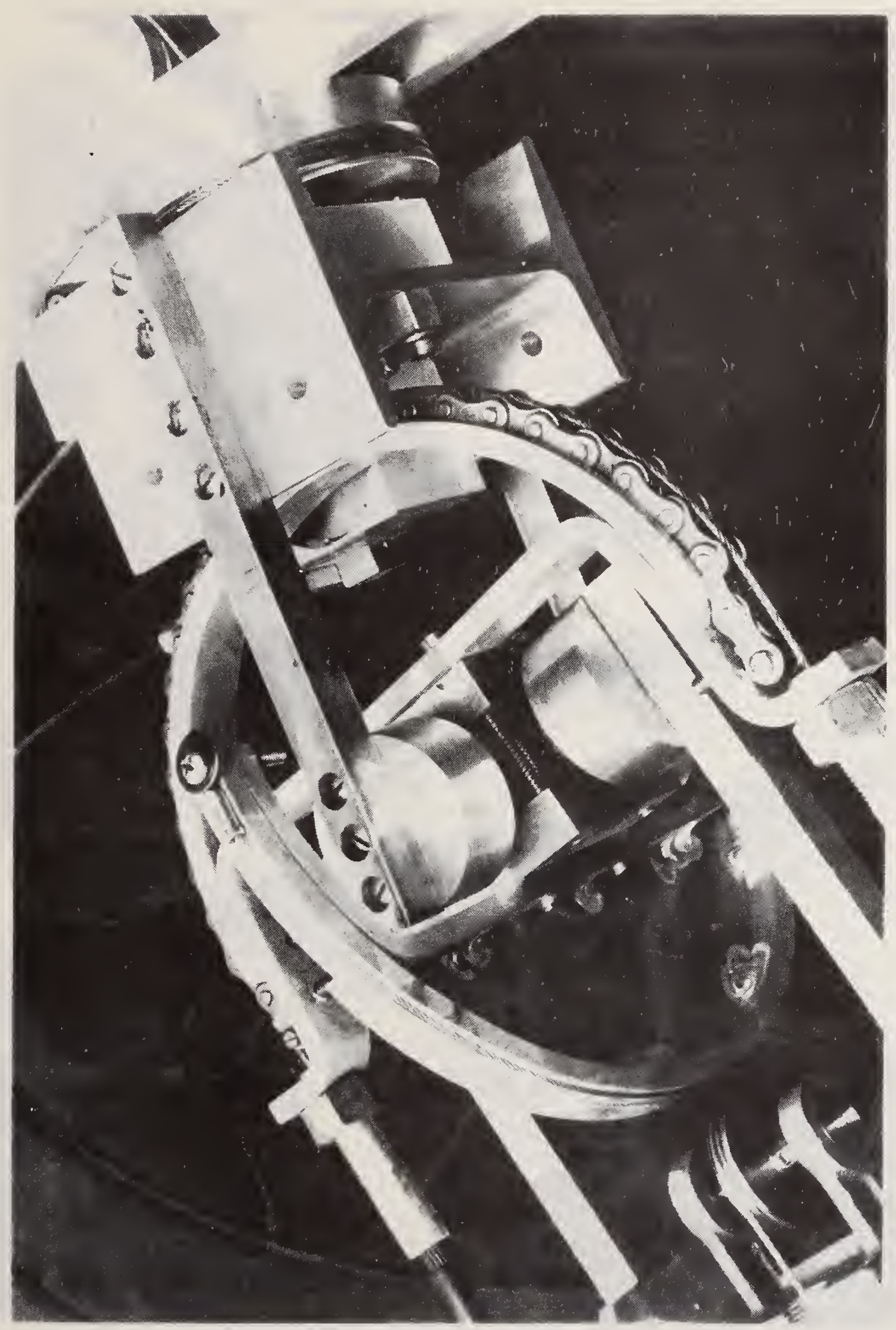


FIGURE 8

Wrist Roll Detail 


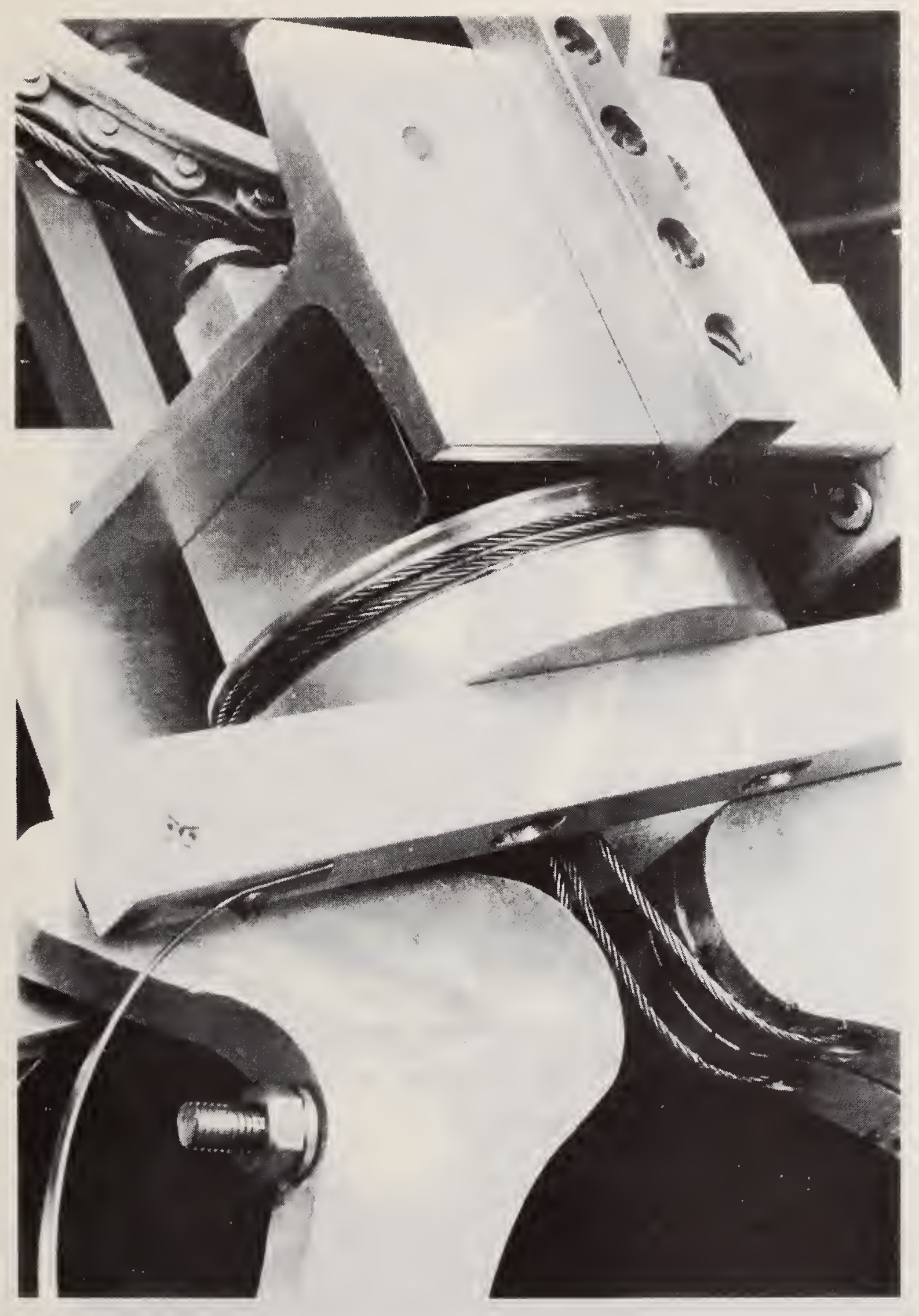




\section{FIGURE 9}

\section{Grip Detail}

The lights are attached for depth cuing to the operator when using remote TV.

This picture shows the spring opening of the hand and the operating cable attachment. 


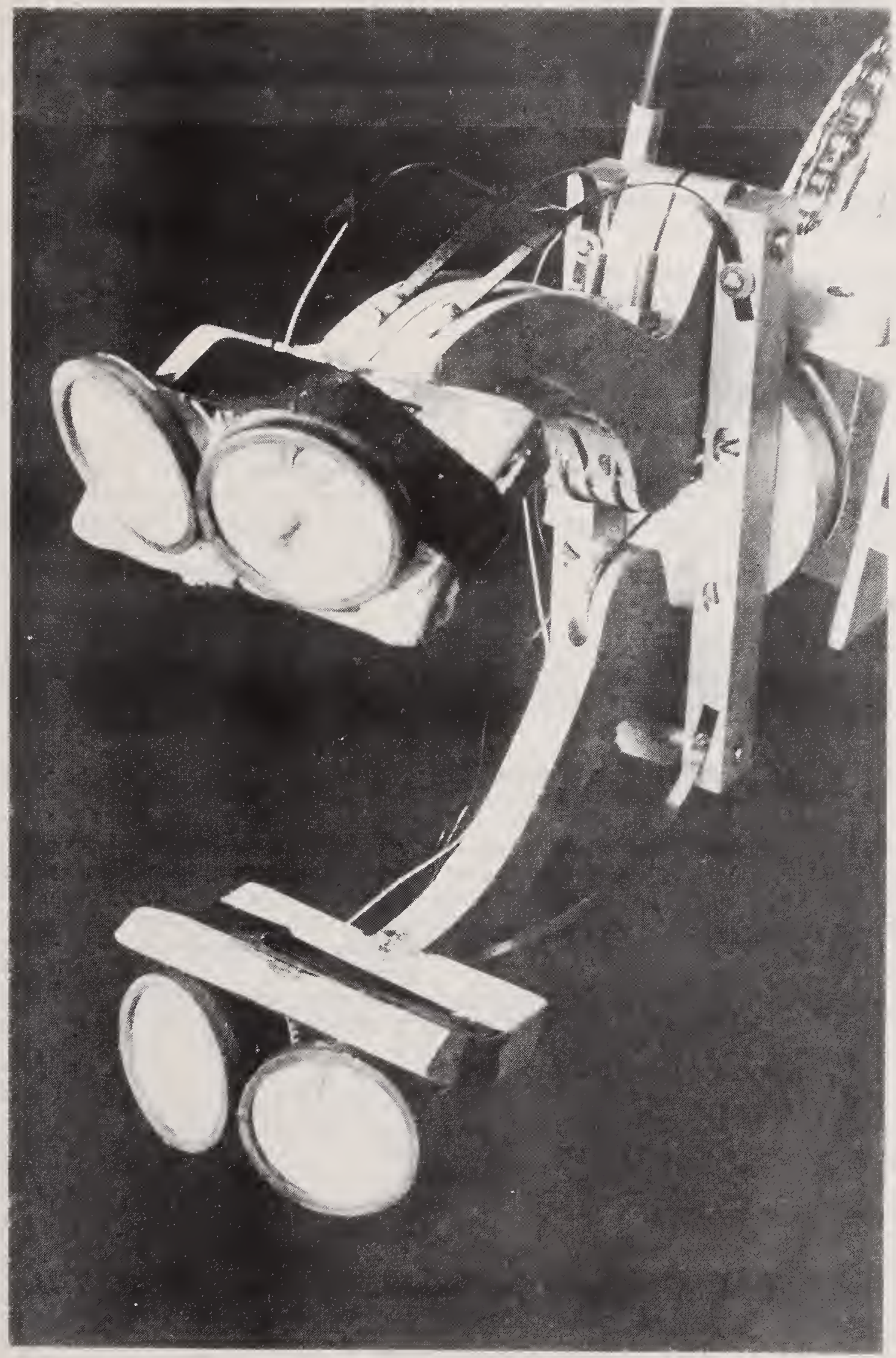


Each of the joints in the arm and hand are servoed. The operator, using a TV monitor, works the manipulator with a master control with the same degrees of freedom as the remote robot. This is shown in Figure 10. The arm $7 \mathrm{ift}$ is on a counterbalanced beam; the flexflex-roll wrist joints are in a gimbled cage with the axes coincident with the operator's wrist. A drill handle is used for the operator to grasp and the trigger controls the grip function.

A potentiometer on each joint provides a position command. The electronics then drive the robot motors to the same relative positions. Thus every motion of the hand and arm of the operator is duplicated by the robot, providing maximum ease of control.

The wheels are driven with rate controls using a joystick control. Forward and back motions drive the motors together; turning the joystick from side to side causes differential drive signals and hence steers the vehicle.

Rate controls for the wheels were originally integrated with the master controls for the arm and hand; later only the vehicle joystick was used to control the wheel drive motors.

Absolute position servoing is difficult for the wheel motions. Using a rate control mode for vehicle motions leaves the wheels in an indeterminate angular position when the wheels are stopped. If potentiometers were located on the master and robot wheels, some means of coping with the arbitrary offset (such as a microcomputer) would be needed when switching to position control. This becomes expensive. It is not felt that rate controls on the wheels degrade the performance enough to warrant the extra expense of position servoing of the wheels.

To provide position feedback to the servo circuits, 10 turn potentiometers are mounted on the output shafts of each motor for the arm and hand functions, as shown in Figure 11. Note that this mounting position avoids any possible instability in the servos from mechanical elasticity in the cables or joints.

The electronics are shown in a drawing set (that is not a part of this report) and in Fiqures 12 and 13 . There are three types of boards:

1. Amplifier boards. These boards contain the basic servo circuits. The voltage representing the position of the master and the feedback voltage representing the actual position of the robot joint are compared. The absolute value of the error signal is modulated at 60 cycles and drives a triac. The sign of the error signal is derived to drive a relay which switches the motor direction.

2. Sawtooth and Feedback Boards. These provide the basic 60 cycle signals from the line voltage and provide current feedback for current limitina to prevent overheating.

3. Relay/triac boards. The motors are driven with triacs. Relays switch motor direction. A 4 triac design would eliminate the relays; relays were used to simplify the basic design on a first model. 
FIGURE 10

\section{Master Control}

Every motion of the operator's hand is duplicated by the robot. Each joint of the master corresponds to one of the LMR. A potentiometer is used to measure the position of each joint. The grasp function is controlled by the trigger in the hand grip. 


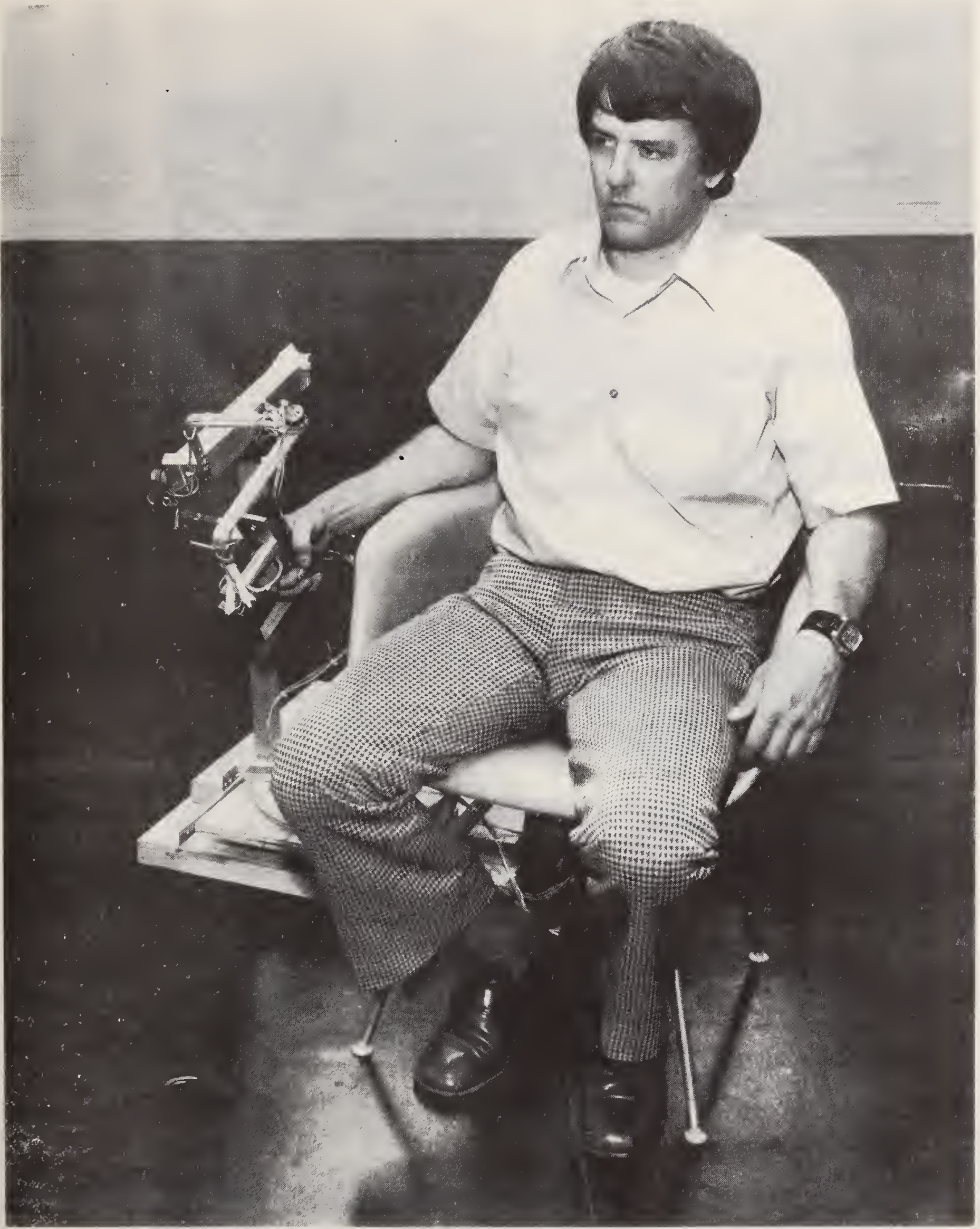


FIGURE 11

\section{Feedback Potentiometer Mounting}




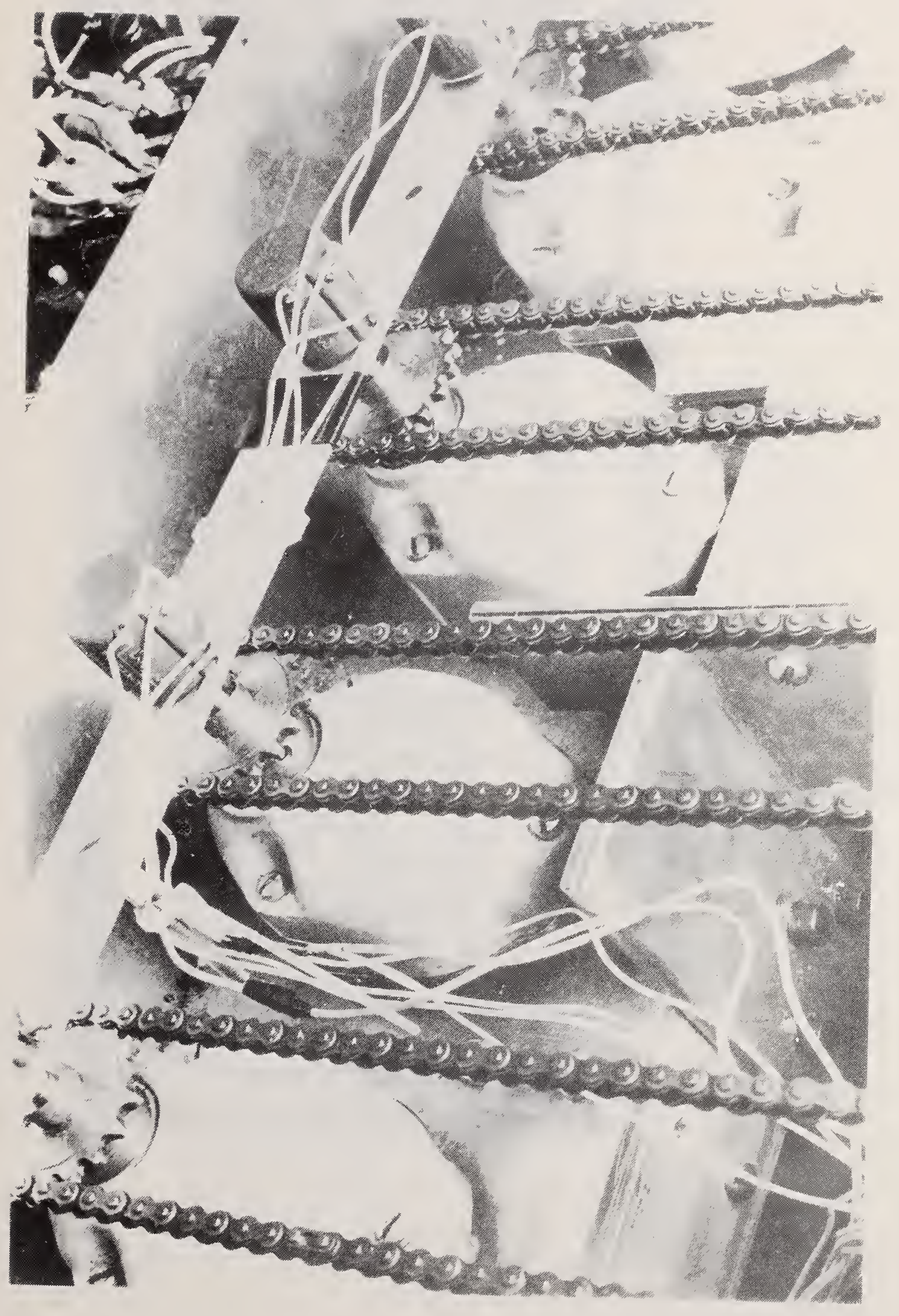


FIGURE 12

Bottom View of Electronic Card Rack 


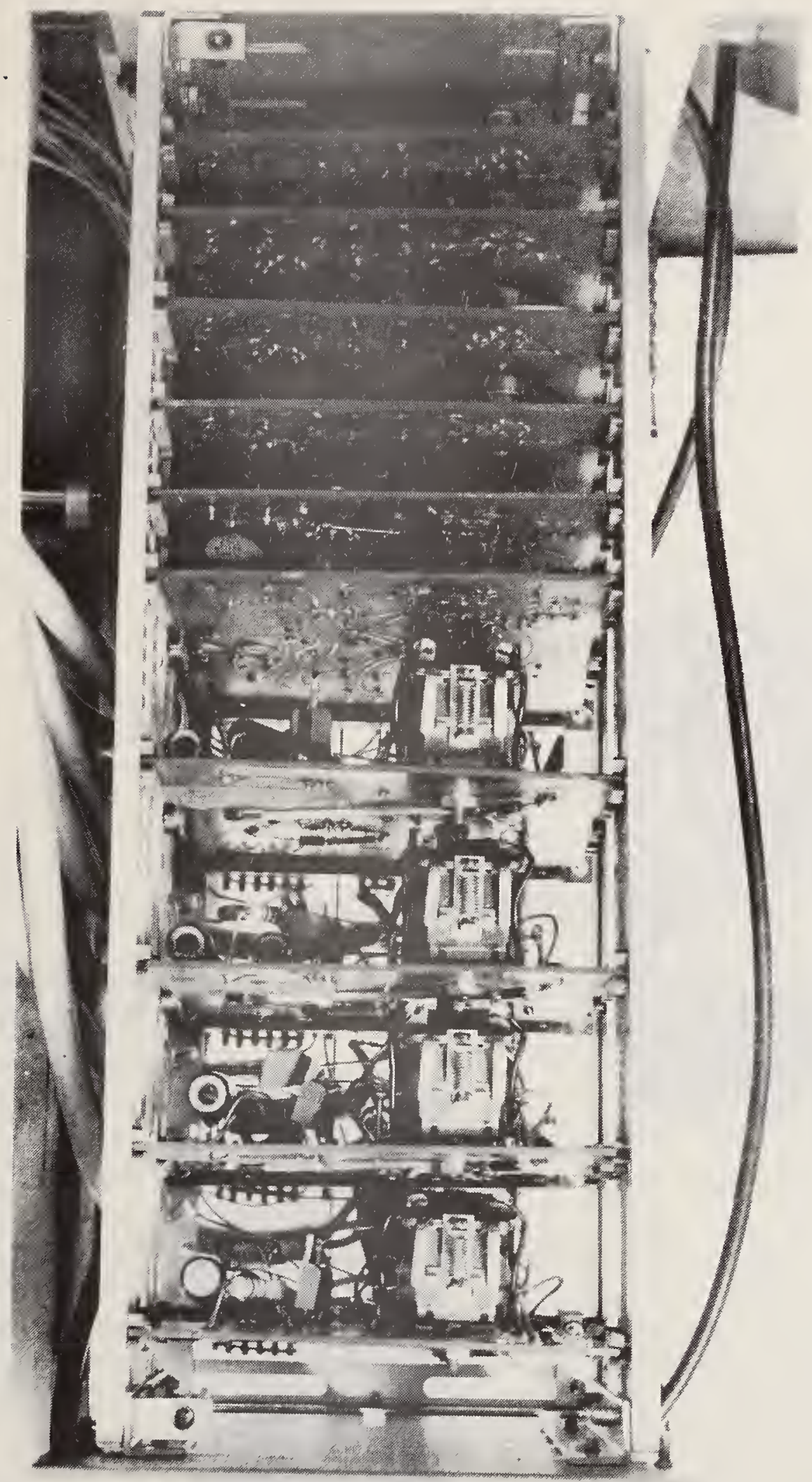


FIGURE 13

\section{Electronic Printed Circuit Cards}

There are three types of boards. At the top is a relay-triac board; at the right is an amplifier board, and at bottom is a sawtooth-feedback board. Their functions are described in the text. 

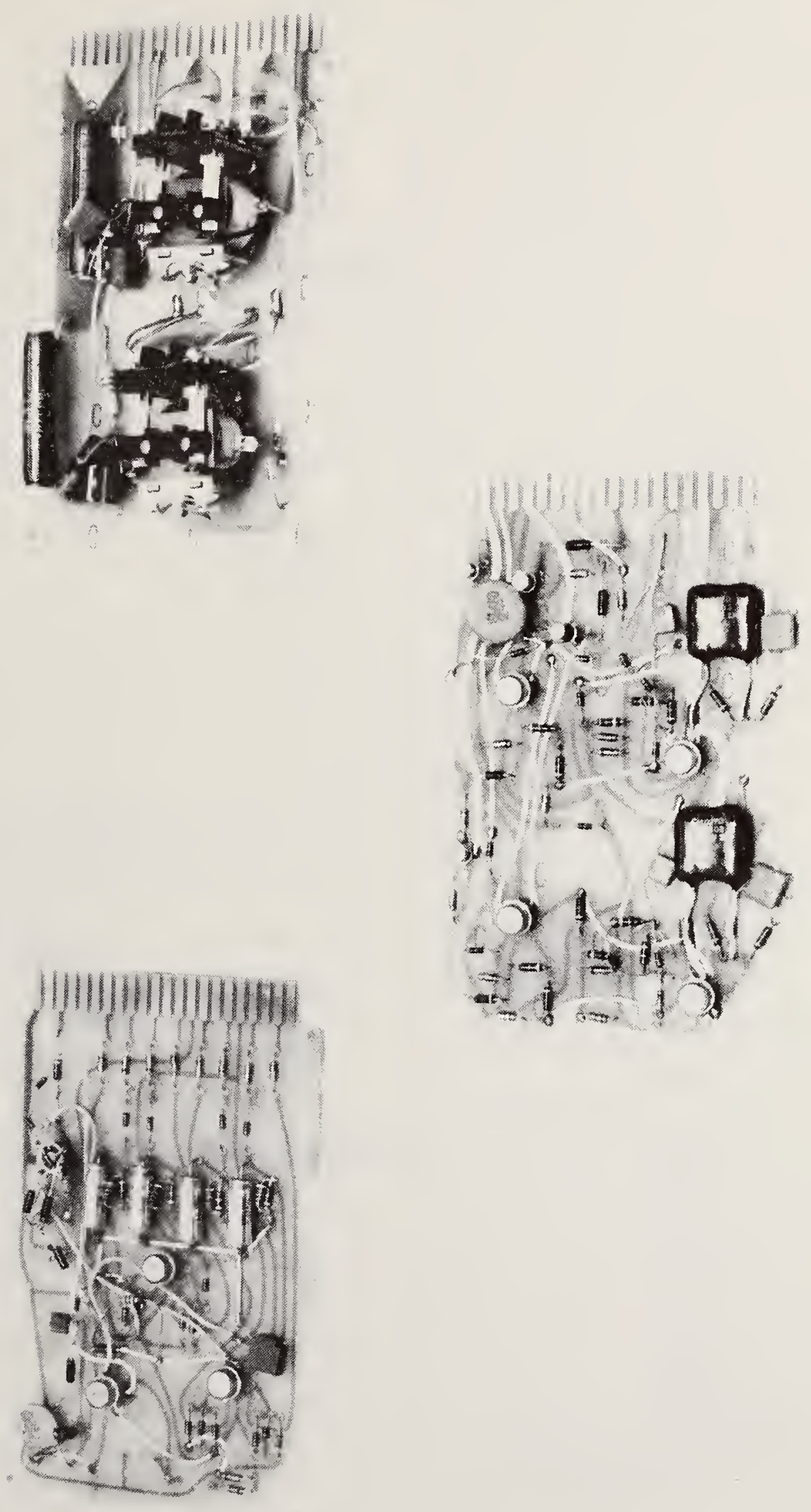



\section{TABLE 1}

\section{LOW COST MOBILE ROBOT}

\section{Parts Costs}

Mechanical

Wire Cables

$\$ 104$

Bearings, pillow blocks, shafts, bushings

130

Chains, spockets

184

Bal1 Bushings

Wheels

Subtota]

19

$\$ 517$

\section{Electrical}

Triacs

$\$ 10$

Opamps

40

Pots

42

Relays

43

Power supply

PC Boards, card racks, cables

Miscellaneous capacitors, resistors, etc.

Dri 11s

$$
\begin{aligned}
& 3 / 8 \text {, reversing }(7) \\
& 3 / 8 \text { (2) for gear boxes } \\
& 1 / 4 \text { (5) for gear boxes }
\end{aligned}
$$

Subtotal

Shops costs (including metal stock, initial drawings, fabrication, assembly, modifications)

Total parts cost of prototype system

Estimated cost for single replica

$\$ 2500$ each

Estimated cost for 10 replicas

$\$ 2000$ each

Estimated cost for 100 replicas 
NBS.114A IREV. 7.73)

\begin{tabular}{|c|c|c|c|}
\hline $\begin{array}{l}\text { U.S. DEPT. OF COMM. } \\
\text { BIBLIOGRAPHIC DATA } \\
\text { SHEET }\end{array}$ & $\begin{array}{l}\text { 1. PUIBI.IC ATION OR RI:PORT NO. } \\
\text { NBSIR 76-995 }\end{array}$ & $\begin{array}{l}\text { 2. Gov't Accession } \\
\text { No. }\end{array}$ & 3. Recipient's Accession No. \\
\hline \multirow{2}{*}{\multicolumn{3}{|c|}{$\begin{array}{l}\text { 4. TITLE AND SUBTITLI: } \\
\text { GUIDELINES FOR THE DESIGN AND PROCUREMENT } \\
\text { OF A LOW COST MOBILE ROBOT }\end{array}$}} & $\begin{array}{l}\text { 5. Publication Datc } \\
\text { December } 1975\end{array}$ \\
\hline & & & 6. Performing Organization Code \\
\hline \multirow{3}{*}{\multicolumn{3}{|c|}{$\begin{array}{l}\text { 7. AUTHOR(S) } \\
\text { John M. EVanS, Ir Ph. D. and James S } \\
\text { 9. PERFORMING ORGANIZATION NAME AND ADDRESS } \\
\text { NATIONAL BUREAU OF STANDARDS } \\
\text { DEPARTMENT OF COMMERCE } \\
\text { WASHINGTON, D.C. } 20234\end{array}$}} & $\begin{array}{l}\text { 8. Perforning Organ. Repore No. } \\
\text { NBSIR 76-995 }\end{array}$ \\
\hline & & & 10. Projcet/Task/Work Unii No. \\
\hline & & & 11. Contract/Girant No. \\
\hline \multicolumn{3}{|c|}{$\begin{array}{l}\text { 12. Sponsoring Organization Name and Complete Address (Street, City, State } \\
\text { Naval Explosive Ordnance Disposal Facility } \\
\text { Indian Head, Maryland } 20640\end{array}$} & $\begin{array}{l}\text { 13. Type of Report \& Period } \\
\text { Covered } \\
\text { Final } \\
\text { 14. Sponsoring Agency Code }\end{array}$ \\
\hline
\end{tabular}

15. SUPPLFMENTARY NOTES

16. ABSTRACT (A 200-word or less factual summary of most significant information. If document includes a significant bibliography or literature survey, mention it here.) The Office of Developmental Automation and Control Technology of the Institute for Computer Sciences and Technology of the National Bureau of Standards works to assist other Government agencies in the efficient application of automation systems to meet their mission objectives. The goal of the program is to stim ulate the use of automation to improve productivity and job safety. The products of the program are consulting and advisory services, standards and guidelines, and performance specifications for the procurement of manipulators and other automation systems.

Since FY1973 the National Bureau of Standards has been supporting the Naval Explosive Ordnance Disposal Facility in the development of remote control manipulator systems for handling explosive ordnance. The use of remote automation systems allows human operators to remain in a safe location while only the mechanical robot system is directly exposed to the hazardous environment. This is a typical example of the use of automatid manipulators to improve job safety.

One of the manipulator systems delivered to the Navy under the project is the Low cost Mobile Robot. This robot is designed around commercially available components for minimum cost. This system could be procured for one tenth the cost of other presently available manipulator systems.

This report discusses the design philosophy and provides performance specifications for the LMR. Together with mechanical drawings and circuit diagrams (which are not a part of this report), these specifications are intended for future development and procurement of such systems by the Navy. 17. KEY WORDS (six to twelve entries; alphabetical order; capitalize only the first letter of the first key word unless a proper
name; separated by semicolons)

Guidelines; manipulator; ordnance handling; procurement specifications; remote contro 1; robot 